\title{
Partial Deletion of the cAMP Response Element-Binding Protein Gene Promotes Alcohol-Drinking Behaviors
}

\author{
Subhash C. Pandey, Adip Roy, Huaibo Zhang, and Tiejun Xu \\ Department of Psychiatry, The Psychiatric Institute, University of Illinois at Chicago and Veterans Affairs Chicago Health Care System, Chicago, Illinois \\ 60612
}

The cAMP response element-binding protein (CREB) gene transcription factor has been shown to play a role in the synaptic plasticity associated with drug addictive behaviors; however, the causal role of the CREB gene in alcohol-drinking behaviors is unknown. The present investigation evaluated alcohol-drinking behaviors in mice that are haplodeficient in CREB as a result of targeted CREB $(\alpha$ and $\Delta)$ gene disruption. It was found that CREB-haplodeficient $(+/-)$ mice have higher preference for ethanol but not for sucrose solution than wild-type $(+/+)$ littermates. The functional aspects of the CREB gene transcription factor were also investigated by measuring the protein levels of phosphorylated CREB (p-CREB) and the expression of cAMP-inducible genes such as neuropeptide Y (NPY) and brain-derived neurotrophic factor (BDNF). Deletion of the CREB ( $\alpha$ and $\Delta$ ) gene significantly decreases total CREB, p-CREB levels and the expression of NPY and BDNF in the brain structures of CREB-deficient $(+/-)$ mice. It was also found that CREB-deficient $(+/-)$ mice displayed more anxiety-like behaviors and that acute ethanol exposure produced anxiolytic effects and significantly increased protein levels of p-CREB and NPY in the central and medial but not in the basolateral amygdala of wild-type mice, but these effects are attenuated in CREB-deficient mice compared with wild-type mice. These results provide the first direct evidence that a haplodeficiency of the CREB gene is associated with increased alcohol-drinking behaviors. Furthermore, alcohol drinking and anxiety-like behaviors in CREBhaplodeficient mice may possibly be related to decreased expression of NPY and BDNF in the brains of these mice.

Key words: CREB; NPY; BDNF; alcohol preference; anxiety; alcoholism

\section{Introduction}

Alcohol addiction is a major public health concern worldwide (National Institute on Alcohol Abuse and Alcoholism, 1993). Genetically, alcohol addiction represents a complex disease, and the available evidence suggests that genetic factors play an important role in the development and maintenance of alcoholdrinking behaviors (Cloninger, 1987; Thome et al., 2000; Radel and Goldman, 2001). Furthermore, higher innate anxiety levels play a crucial role in the initiation and maintenance of alcoholdrinking behaviors, and this may be related to the anxiolytic action of ethanol (Bibb and Chambless, 1986; Koob, 2003; Pandey, 2003). The molecular mechanisms responsible for this association are unkown. The cAMP response element-binding protein (CREB) gene transcription factor represents an important molecular link between neurotransmitter receptor activation and the orchestration of gene expression (Silva et., 1998; Nestler, 2001; Lonze and Ginty, 2002). Functionally, CREB is regulated via phosphorylation at serine-133 by cAMP-dependent protein ki-

\footnotetext{
Received Dec. 17, 2003; revised March 30, 2004; accepted April 15, 2004.

This study was supported by grants from the National Institute on Alcohol Abuse and Alcoholism (AA-10005, AA13341) and the Department of Veterans Affairs (Merit Review Grant) to S.C.P. We thank Dr. Alcino Silva, University of California at Los Angeles, for providing CREB breeder mice and for his suggestions on this manuscript. We also thank Kaushik Misra for his help with the art work.

Correspondence should be addressed to Dr. Subhash C. Pandey, Department of Psychiatry, University of Illinois at Chicago, and Veterans Affairs Chicago Health Care System, 820 South Damen Avenue (M/C 151), Chicago, IL 60612 E-mail: scpandey@uic.edu.

DOI:10.1523/JNEUROSCI.5557-03.2004

Copyright $\odot 2004$ Society for Neuroscience $\quad 0270-6474 / 04 / 245022-\bullet \$ 15.00 / 0$
}

nase A (PKA), by $\mathrm{Ca}^{2+} /$ calmodulin-dependent protein kinases, and by ribosomal $\mathrm{S}_{6}$ kinase via mitogen-activated protein kinase (Silva et al., 1998; Impey et al., 1999; Soderling, 1999; Lonze and Ginty, 2002). Phosphorylated CREB regulates the expression of several downstream cAMP-inducible genes such as neuropeptide Y (NPY) and brain-derived neurotrophic factor (BDNF) (Shieh et al., 1998; Lonze and Ginty, 2002; McClung and Nestler, 2003; Pandey, 2003).

Alterations in the phosphorylation of CREB (serine-133) and in the expression of NPY and BDNF in several brain structures have been shown to be associated with the process of alcohol tolerance and dependence (MacLennan et al., 1995; Yang et al., 1998; Misra et al., 2001; Bison and Crews, 2003; Pandey et al., 2003b). It has been shown that ethanol withdrawal after chronic ethanol exposure leads to significant reductions in CREB phosphorylation and NPY protein levels in various rat brain structures, and decreased CREB phosphorylation and NPY expression in the central amygdala (CeA) might be associated with anxietylike behaviors during ethanol withdrawal (Pandey et al., 2001, 2003b; Zhang and Pandey, 2003). It has also been found that CREB expression and phosphorylation as well as NPY protein levels are lower in amygdaloid brain structures of alcoholpreferring $(\mathrm{P})$ rats compared with alcohol-nonpreferring (NP) rats (Hwang et al., 1999; Pandey et al., 1999). Interestingly, P rats display more anxiety-like behaviors and have higher ethanol preference than NP rats (Li et al., 1993; Stewart et al., 1993). More recently, it was found that infusions of PKA inhibitor in the cen- 
tral amygdala decreased CREB phosphorylation and NPY expression and also provoked anxiety-like behaviors and increased alcohol preference in rats (Pandey et al., 2003b). These previous studies support the notion that CREB and CREB-related target genes may be associated with both anxiety and alcohol preference; however, these studies do not establish a causal role for the CREB gene in alcohol-drinking behaviors or in comorbidity with anxiety behaviors.

To delineate the direct role of CREB in several physiological conditions, mice with targeted gene mutations encoding for CREB have been developed (Bourtchuladze et al., 1994; Hummler et al., 1994; Maldonado et al., 1996). It has been shown that this mutation results in deletion of two isoforms of CREB $(\alpha$ and $\Delta$ ) in CREB knock-out mice (Hummler et al., 1994; Blendy et al., 1996). CREB $\alpha$ and $\Delta$ are major isoforms and are highly abundant in the adult brain (Blendy et al., 1996). Therefore, to establish the role of CREB in alcohol-drinking and anxiety-like behaviors, we used CREB $\alpha$ - and $\Delta$-haplodeficient mice and examined (1) the effects of deletion of the CREB $\alpha$ and $\Delta$ genes on alcohol-drinking and anxiety-like behaviors using CREBdeficient $(+/-)$ and wild-type $(+/+)$ littermate mice, $(2)$ the effects of CREB deletion on the expression of CREB target genes, such as NPY and BDNF in the brain structures of CREB-deficient mice, and (3) the effects of acute alcohol on anxiety-like behaviors and on CREB phosphorylation and the expression of NPY in the amygdaloid structures of CREB-deficient and wild-type mice.

\section{Materials and Methods}

Breeding and genotyping of CREB mice. CREB ( $\alpha$ and $\Delta$ ) knock-out mice were generated from 129/SVJ mice and then backcrossed with C57BL/6 mice (Bourtchuladze et al., 1994; Hummler et al., 1994). These CREB mice were crossed several times to mice with a C57BL/6 genetic background; the heterozygotic mice then were mated with $129 / \mathrm{SVJ}$ mice, and the resultant heterozygous mice (F1 generation) were mated to get heterozygous and wild-type littermate mice (F2 generation). All mice used in the present study were genetically matched for their background, and only the F2 generation (mixed C57BL/6 and 129/SVJ background) male mice (3-6 months old) were used in all experiments. Genotyping was performed by PCR as described by other investigators (Bourtchuladze et al., 1994). The DNA samples isolated from tail tips were used for PCR amplifications $\left[93^{\circ} \mathrm{C}\right.$ for $2 \mathrm{~min} ; 93^{\circ} \mathrm{C}$ for $30 \mathrm{sec} ; 47^{\circ} \mathrm{C}$ for $30 \mathrm{sec} ; 72^{\circ} \mathrm{C}$ for $1 \mathrm{~min}$ (total of $40 \mathrm{cycles}$ ), and then $72^{\circ} \mathrm{C}$ for $10 \mathrm{~min}$ ] to identify the wild-type (150 bp band) and heterozygous $(150+350 \mathrm{bp}$ band) mice. The primers used were as follows: CREB 1: $5^{\prime}$-TAT TGTAGGTAACTAAATGA-3'; CREB 2: 5' -ATGTATTTTTATACCTGGGC-3'; NEO: 5' TGATGGATACTTTCTCGGCA- ${ }^{\prime}$. We used CREB-haplodeficient mice because ethanol dependence in rats produces a $\sim 32 \%$ reduction in CREB phosphorylation in the brain, and pharmacologically inhibiting PKA in the central amygdala produces a $\sim 30 \%$ reduction in CREB phosphorylation and, in addition, increases anxiety-like behaviors and alcohol preference in rats (Pandey et al., 2003b).

Ethanol and sucrose preference procedures. Ethanol preference was measured by the two-bottle free-choice paradigm used by us (Misra and Pandey, 2003) and other investigators (Thiele et al., 1998, 2000). Mice had ad libitum access to food and water in two bottles and were habituated to drink water from either bottle. Bottle positions were changed daily so that the mice would not develop a position habit. Once they started drinking water equally from either bottle, mice were provided with $7 \%$ ethanol solution in one bottle and water in the other bottle daily for $3 \mathrm{~d}$, and then concentrations of ethanol were increased to $9 \%$ for $3 \mathrm{~d}$ and to $12 \%$ for another $3 \mathrm{~d}$. Consumption of ethanol and water was measured daily at 6 P.M., and fresh water and ethanol (7, 9, or 12\%) solution in water were provided every day. The mean percentage of ethanol intake and the percentage of water intake were calculated from their total fluid intake for $3 \mathrm{~d}$ for 7,9 , and $12 \%$ ethanol. Sucrose preference was measured by the two-bottle free-choice paradigm using a similar proce- dure as described above for ethanol in separate batches of CREBhaplodeficient $(+/-)$ and wild-type $(+/+)$ littermate mice. They were provided with a $2 \%$ sucrose solution in one bottle and water in the other bottle daily for $3 \mathrm{~d}$, and then the sucrose concentration was increased to $4 \%$ for $3 \mathrm{~d}$. The mean percentage of sucrose intake and the percentage of water intake were calculated from their total fluid intake for $3 \mathrm{~d}$ of 2 and $4 \%$ sucrose. We also measured the body weights of mice in all experiments and found no significant differences in body weights among the genotypes.

Measurement of anxiolytic effects of ethanol by elevated plus-maze test. The CREB-haplodeficient and littermate wild-type mice were injected intraperitoneally with $2 \mathrm{gm} / \mathrm{kg}$ ethanol (ethanol diluted with normal saline) or normal saline. One hour after ethanol injection, anxiety-like behavior was measured. We also measured blood ethanol levels $1 \mathrm{hr}$ after ethanol injection using an Analox alcohol analyzer (Lunenburg, MA). The elevated plus-maze (EPM) test procedure was used to measure anxiety-like behaviors as described previously (Misra and Pandey, 2003). EPM test results were expressed as the mean \pm SEM of the percentage of open-arm entries and the mean percentage of the time spent on the open arms (open-arm activity). The general activity of mice was represented by the total number of entries onto the closed and open arms of the EPM. Total CREB, $p$-CREB, BDNF, NPY, and neuron-specific neuronal marker gold immunolabeling. Protein levels of CREB, p-CREB, BDNF, NPY, and neuron-specific neuronal marker $(\mathrm{NeuN})$ were determined by the gold-immunolabeling histochemical procedure as described previously (Misra et al., 2001; Pandey et al., 2001, 2003b; Roy and Pandey, 2002; Misra and Pandey, 2003). The polyclonal antibodies for CREB and p-CREB (Ser-133) were purchased from Upstate Biotechnology (Lake Placid, NY). The anti-NPY antibody (Ab) was purchased from Diasorin (Stillwater, MN), and the Abs for BDNF were purchased from Santa Cruz Biotechnology (Santa Cruz, CA). The NeuN Ab was purchased from Chemicon International (Temecula, CA). Mice were anesthetized and then perfused intracardially with normal saline $(40 \mathrm{ml})$, followed by 100 $\mathrm{ml}$ of $4 \%$ ice-cold paraformaldehyde fixative. Brains were removed and placed in fixative for $20 \mathrm{hr}$ at $4^{\circ} \mathrm{C}$. After fixation, brains were soaked in $10 \%$, followed by $20 \%$ and $30 \%$ sucrose (prepared in $0.1 \mathrm{~m}$ phosphate buffer, $\mathrm{pH}$ 7.4). Brains were frozen, and $20 \mu \mathrm{m}$ coronal sections were prepared using a cryostat. These sections were then placed in $0.01 \mathrm{M}$ PBS at $4^{\circ} \mathrm{C}$ and used for gold immunolabeling. The quantification of goldimmunolabeled protein was performed using an Image Analysis System (Loats Associates, Westminster, MD) connected to a light microscope that calculated the number of immunogold particles per $100 \mu \mathrm{m}^{2}$ area of a defined brain structure at high magnification $(100 \times)$. The threshold of each image was set up in such a way that an area without staining would give zero counts. Under this condition, immunogold particles in the defined brain structures of three adjacent brain sections of each mouse were counted, and then values were averaged for each mouse.

In situ RT-PCR for NPY and BDNF mRNA measurements. Mouse brain sections were used to determine mRNA levels using in situ RT-PCR, as reported previously (Pandey et al., 2003b; Zhang and Pandey, 2003). Briefly, the procedure was as follows. Floating brain sections $(40 \mu \mathrm{m}$ thickness) were treated with proteinase $\mathrm{K}(1 \mu \mathrm{g} / \mathrm{ml}$ in $1 \times$ PBS containing $0.05 \%$ Triton $\mathrm{X}-100$ ) for $15 \mathrm{~min}$ at $37^{\circ} \mathrm{C}$ and then subjected to DNase digestion. After the sections were washed with $1 \times \mathrm{PBS}$, they were transferred to PCR tubes containing $100 \mu \mathrm{l}$ of PCR mixture (Applied Biosystems, Foster city, CA) and reverse transcribed for $1 \mathrm{hr}$ at $42^{\circ} \mathrm{C}$ with reverse transcriptase in the presence of oligo-dT. In the negative sections, reverse transcriptase enzyme was not added. The PCR was performed with Taq DNA polymerase enzyme and 36-38 pmol of each NPY primer (primers 5'-TAGGTAACAAACGAATGGGG-3' and 5'-AGGATGAGATGAGATGTGGG-3') or BDNF primer (primers $5^{\prime}$-TAACGGCGGCA GACAAAAAGACT-3' and 5'-GTGTCTATCCTTATGAATCGCCAGCCAA- $3^{\prime}$ ) and 1 mM each of NTP and dTTP, except that the dTTP was replaced by digoxigenin (DIG)-11-dUTP [PCR conditions for NPY: $94^{\circ} \mathrm{C}$ for $3 \mathrm{~min} ; 94^{\circ} \mathrm{C}$ for $45 \mathrm{sec} ; 60^{\circ} \mathrm{C}$ for $45 \mathrm{sec} ; 72^{\circ} \mathrm{C}$ for $45 \mathrm{sec}$ (total of 25 cycles), and then $72^{\circ} \mathrm{C}$ for $7 \mathrm{~min}$; PCR conditions for BDNF: $94^{\circ} \mathrm{C}$ for $2 \mathrm{~min} ; 94^{\circ} \mathrm{C}$ for $30 \mathrm{sec} ; 57^{\circ} \mathrm{C}$ for $30 \mathrm{sec} ; 72^{\circ} \mathrm{C}$ for $90 \mathrm{sec}$ (total of $30 \mathrm{cycles}$ ), and then $72^{\circ} \mathrm{C}$ for $10 \mathrm{~min}$ ]. After PCR, sections were mounted on slides, and NPY- or BDNF-positive cell bodies were detected using alkaline 

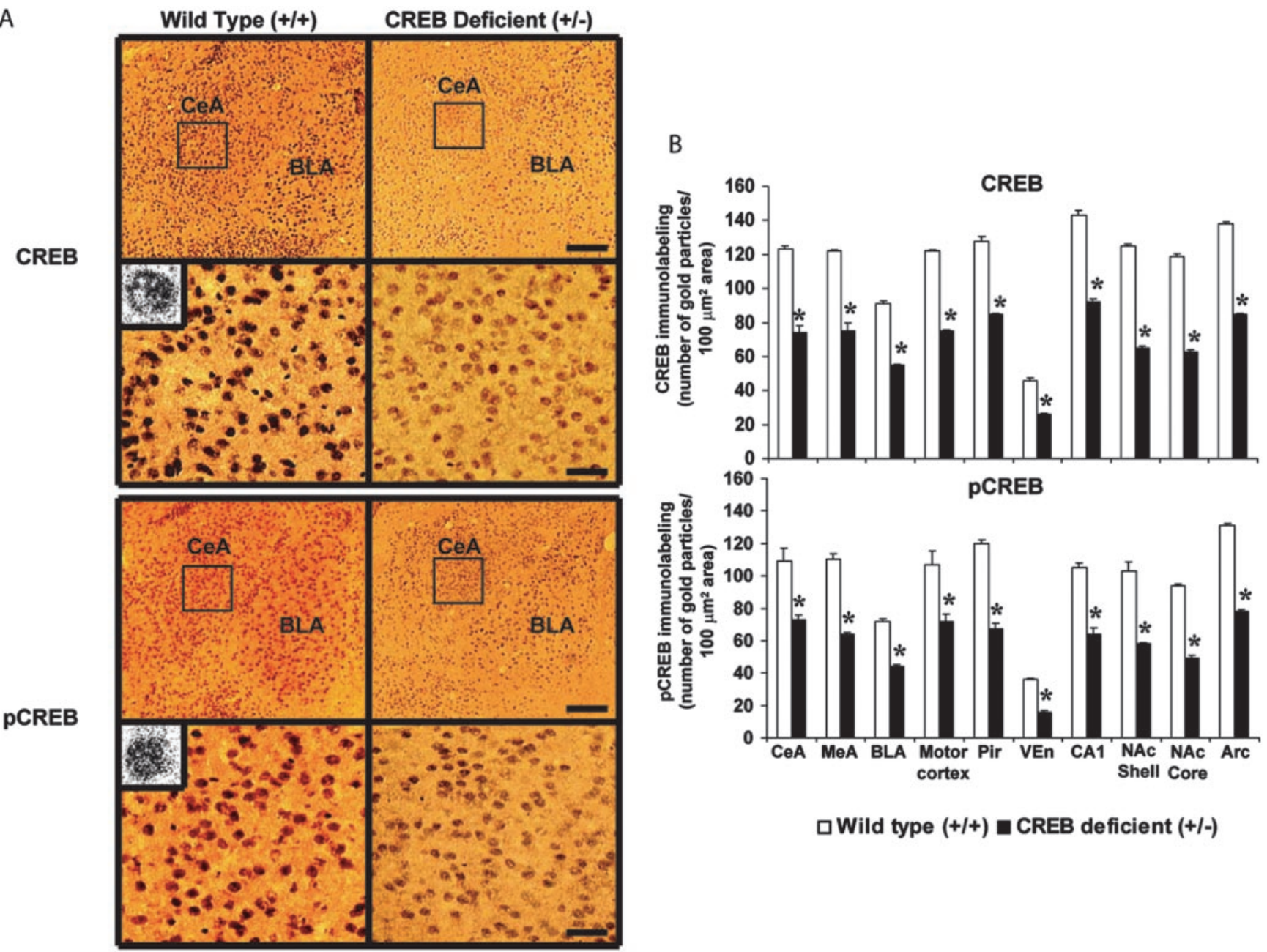

$\square$ Wild type (+/+) $\square$ CREB deficient (+/-)

Figure 1. A, Photomicrographs at low magnification showing CREB and p-CREB gold immunolabeling in the amygdaloid structures (top panel of (REB and p-CREB photomicrographs) of CREB-haplodeficient $(+/-)$ and wild-type $(+/+)$ mice. Scale bar, $180 \mu \mathrm{m}$. Inset areas for the central amygdala in the top panel of CREB and $p$-CREB labeling are shown at higher magnification in the bottom panel of CREB and p-CREB immunolabeling, respectively. Scale bar, $40 \mu \mathrm{m}$. The inset for CREB and p-CREB labeling in the central amygdala of wild-type mice (bottom panel) indicates immunogold particles within a single nucleus at high magnification. B, Quantitation of total CREB and p-CREB gold immunolabeling (number of immunogold particles per $100 \mu \mathrm{m}^{2}$ area) in several brain structures [cortical (motor cortex, piriform cortex, ventral endopiriform nucleus), amygdaloid (central, medial, basolateral amygdala), hippocampal (CA1), nucleus accumbal (shell and core structures), and hypothalamic (arcuate nucleus)] of alcohol-naive CREB-haplodeficient $(+/-)$ and wild-type $(+/+)$ mice. Values are the mean \pm SEM of three mice in each group. ${ }^{*}$ Significantly different from wild-type mice ( $p<0.001)$. Pir, Piriform cortex; VEn, ventral endopiriform nucleus; CeA, central amygdala; MeA, medial amygdala; BLA, basolateral amygdala; NAc nucleus accumbens; Arc, arcuate nucleus.

phosphatase-conjugated anti-DIG $\mathrm{Ab}$ and subsequent staining of the complex with the specific substrate nitroblue tetrazolium chloride/5bromo-4-chloro-3-indoyl-phosphate (Roche Molecular Biochemical, Mannheim, Germany). The optical density (OD) of positive cell bodies was calculated with an Image analyzer (Loats Associates). The OD of the negative brain sections was subtracted from the positive brain sections. The OD of positive cell bodies in the defined brain structures of three adjacent brain sections of each mouse was calculated, and values were averaged for each mouse. The results are represented as the mean OD per 100 pixel area.

Data analysis. Specific subgroup (between wild-type and CREBhaplodeficient mice) comparisons were performed using the nonparametric Mann-Whitney $U$ Test. The differences between these groups were also analyzed by ANOVA followed by multiple comparisons versus wild-type mice with Dunnett's test as well as post hoc comparisons between the groups by Tukey's test.

\section{Results}

Protein levels of p-CREB in CREB-haplodeficient $(+/-)$ and wild-type littermate mice

Because it has been shown that complete deletion of the major isoforms of CREB ( $\alpha$ and $\Delta$ isoforms) is associated with upregu- lation of CREB- $\beta$ (minor isoform) in the brain (Hummler et al., 1994; Blendy et al., 1996), we evaluated the basal protein levels of total and phosphorylated CREB (Ser-133) in the brain of CREBhaplodeficient and wild-type littermate mice. Here we have shown CREB and p-CREB-positive nuclei in the central amygdala of CREB-haplodeficient $(+/-)$ and wild-type $(+/+)$ mice (Fig. 1A) as representative brain regions. It was found that both total CREB and p-CREB levels are lower throughout the brain regions (cortical, hippocampal, amygdaloid, nucleus accumbal, and hypothalamic structures) of CREB-haplodeficient mice compared with wild-type mice (Fig. $1 A, B$ ). These results provide evidence that the CREB-haplodeficient mice have lower levels of total and functional CREB across various brain regions.

Expressions of CREB-related target genes in CREBhaplodeficient $(+/-)$ and wild-type littermate mice It has been shown that NPY and BDNF are CREB target genes (Shieh et al., 1998; McClung and Nestler, 2003; Pandey, 2003). We therefore evaluated whether haplodeletion of CREB ( $\alpha$ and $\Delta$ isoforms) is associated with the decreased expression of CREB 

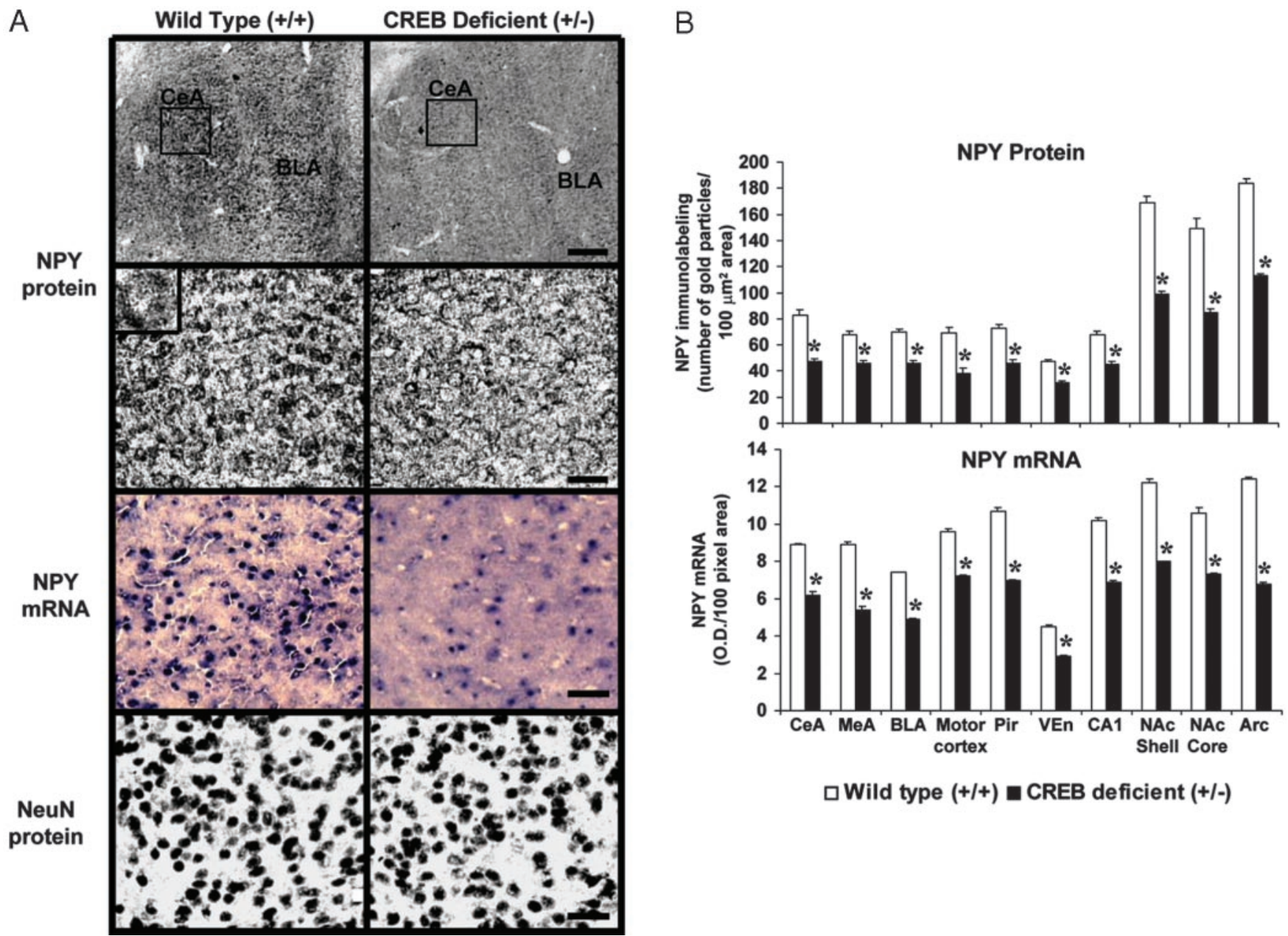

$\square$ Wild type (+/+) $\square$ CREB deficient (+/-)

Figure 2. A, Photomicrographs at low magnification showing NPY gold immunolabeling in the amygdaloid structures (first panel) of (REB-haplodeficient $(+/-)$ and wild-type $(+/+)$ mice. Scale bar, $180 \mu \mathrm{m}$. Inset areas for the central amygdala in the first panel are shown below at higher magnification for NPY immunolabeling in the central amygdala (second panel). Scale bar, $40 \mu \mathrm{m}$. The inset for the central amygdala of wild-type $(+/+)$ mice (second panel) indicates immunogold particles within a cell body at high magnification. Photomicrographs in the third panel show NPY mRNA levels (in situ PCR) in the central amygdala of CREB-haplodeficient $(+/-$ ) and wild-type mice. Scale bar, $40 \mu \mathrm{m}$. Photomicrographs in the fourth panel show NeuN in the central amygdala of (REB-haplodeficient (+/-) and wild-type mice. Scale bar, $40 \mu \mathrm{m}$. B, Quantitation of NPY gold immunolabeling (number of immunogold particles per $100 \mu \mathrm{m}^{2}$ area) and mRNA levels of NPY in the brain structures [cortical (motor cortex, piriform cortex, ventral endopiriform nucleus), amygdaloid (central, medial, basolateral amygdala), hippocampal (CA1), nucleus accumbal(shell and core structures), and hypothalamic (arcuate nucleus)] of alcohol-naive CREB-haplodeficient (+I-) and wild-type mice. Values are the mean \pm SEM of three mice in each group. ${ }^{*}$ Significantly different from wild-type mice $(p<0.001)$. Pir, Piriform cortex; VEn, ventral endopiriform nucleus; CeA, central amygdala; MeA, medial amygdala; BLA, basolateral amygdala; NAc, nucleus accumbens; Arc, arcuate nucleus.

target genes. The expression of NPY and BDNF was measured in the brains of CREB-haplodeficient and littermate wild-type mice. Here we have shown NPY and BDNF expression (mRNA and protein levels) in the central amygdala of CREB-haplodeficient $(+/-)$ and wild-type $(+/+)$ mice (Figs. $2 A, 3 A)$ as representative brain regions. It was found that NPY and BDNF expression (mRNA and protein levels) was lower throughout the brain regions (cortical, hippocampal, amygdaloid, nucleus accumbal, and hypothalamic structures) studied in CREB-haplodeficient mice compared with wild-type mice (Figs. 2B, 3B). These results provide evidence that CREB-haplodeficient mice have a lower expression of CREB target genes such as NPY and BDNF. We also measured the protein levels of NeuN in the brain structures of CREB-haplodeficient and wildtype mice. Here we have shown NeuN-positive nuclei in the central amygdala of CREB-haplodeficient $(+/-)$ and wild type $(+/+)$ mice (Fig. $2 A$, bottom panel) as representative brain regions. It was found that the numbers of neurons are similar and that there is no neuronal loss in the brain structures of CREBhaplodeficient mice (data not shown). These results indicate that decreased expression of NPY and BDNF are not caused by the loss of neurons in the brain structures of CREB-haplodeficient mice.

\section{Alcohol and sucrose preference in CREB-haplodeficient} $(+/-)$ and littermate wild-type mice

We used male CREB-haplodeficient mice $(+/-)$ and matched littermate wild-type ( $\mathrm{F}_{2}$ generation; 3-6 months old) mice to measure alcohol-drinking behaviors using the two-bottle freechoice paradigm. When mice started drinking water equally from either bottle, they were given a continuous free choice of drinking from two bottles, one containing water and the other containing $7 \%$ ethanol in water for $3 \mathrm{~d}$; the concentration of ethanol was then increased to $9 \%$ for $3 \mathrm{~d}$ and to $12 \%$ for $3 \mathrm{~d}$. It was found that CREB-haplodeficient mice consumed significantly higher $(\sim 50 \%)$ amounts of alcohol solution $(7,9$, and $12 \%)$ compared with their respective wild-type littermate mice (Fig. 4A). We also calculated the results in terms of ethanol consumption relative to total fluid intake (ethanol-preference ratio). CREBhaplodeficient $(+/-)$ mice showed a higher preference for 
A

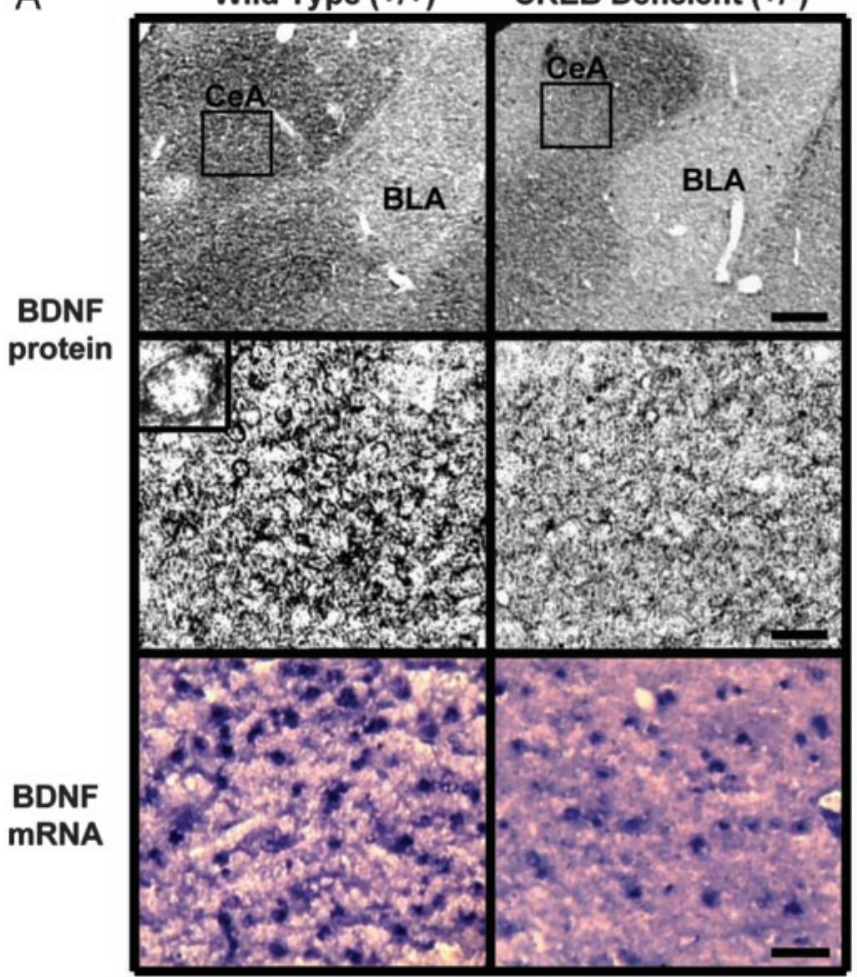

B
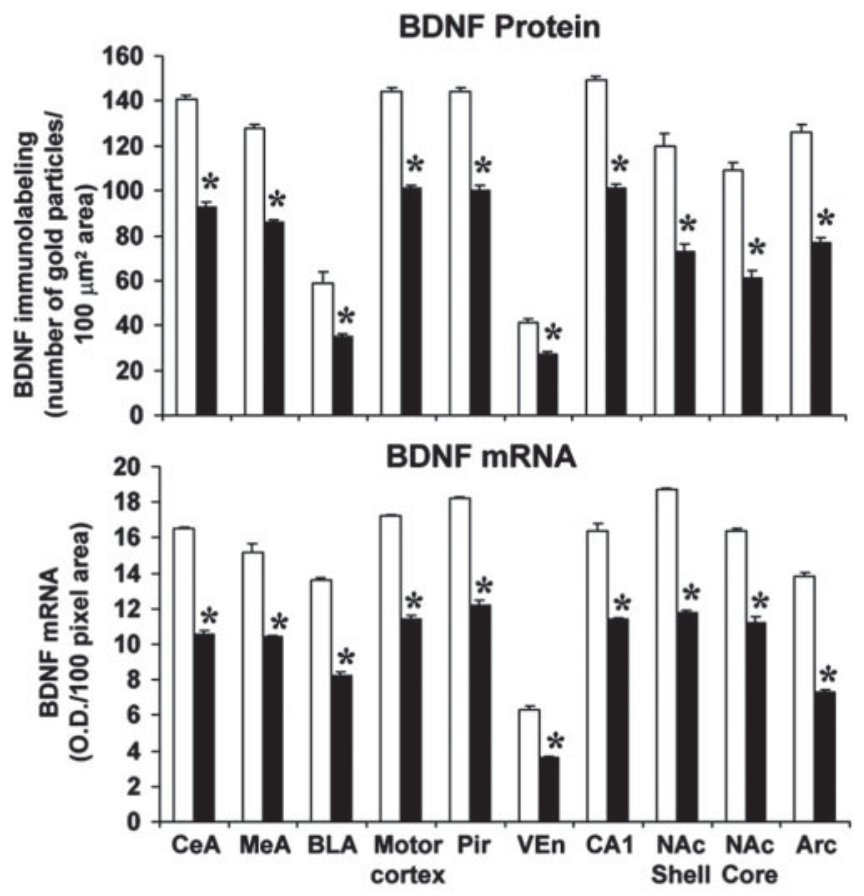

$\square$ Wild type (+/+) $\square$ CREB deficient (+l-)

Figure 3. A, Photomicrographs at low magnification showing BDNF gold immunolabeling in the amygdaloid structures (top panel) of CREB-haplodeficient $(+/-)$ and wild-type $(+/+)$ mice. Scale bar, $180 \mu \mathrm{m}$. Inset areas for the central amygdala in the top panel are shown below at higher magnification for BDNF immunolabeling in the central amygdala (middle panel). Scale bar, 40 $\mu \mathrm{m}$. The inset for the central amygdala of wild-type $(+/-)$ mice (middle panel) indicates immunogold particles within a cell body at high magnification. Photomicrographs in the bottom panel show BDNF mRNA levels (in situ PCR) in the central amygdala of CREB-haplodeficient $(+/-$ ) and wild-type mice. Scale bar, $40 \mu \mathrm{m}$. B, Quantitation of BDNF gold immunolabeling (number of immunogold particles per $100 \mu \mathrm{m}^{2}$ area) and mRNA levels of BDNF in the brain structures [cortical (motor cortex, piriform cortex, ventral endopiriform nucleus), amygdaloid (central, medial, basolateral amygdala), hippocampal (CA1), nucleus accumbal (shell and core structures), and hypothalamic (arcuate nucleus)] of alcohol-naive (REB-haplodeficient ( $+/-$ ) and wild-type mice. Values are the mean \pm SEM of three mice in each group. *Significantly different from wild-type mice $(p<0.001)$. Pir, Piriform cortex; VEn, ventral endopiriform nucleus; CeA, central amygdala; MeA, medial amygdala; BLA, basolateral amygdala; NAc, nucleus accumbens; Arc, arcuate nucleus.

ethanol over water during access to the 7,9 , and $12 \%$ ethanol solutions (Fig. $4 B$ ). These results clearly indicate that CREBhaplodeficient $(+/-)$ mice have a higher preference for ethanol over water compared with their wild-type littermates.

To determine whether increased preference for ethanol is related to taste preference, we measured sucrose preference in separate groups of mice using the two-bottle free-choice paradigm. It was found that sucrose ( 2 or $4 \%$ ) consumption was similar among the genotypes (Fig. 4C). These results indicate that increased ethanol consumption by CREB-haplodeficient mice is not related to taste preference.

\section{Anxiety-like behaviors and p-CREB and NPY: effects of acute ethanol injection}

To determine the association between anxiety-like behaviors and alcohol intake, we also measured the anxiolytic effects of ethanol and injected $2 \mathrm{gm} / \mathrm{kg}$ ethanol (intraperitoneally) or normal saline in CREB-haplodeficient and littermate wild-type mice. After $1 \mathrm{hr}$ of ethanol injection, anxiety-like behavior was measured using the EPM test. It was found that CREB-haplodeficient mice displayed more baseline anxiety-like behaviors (decreased openarm activity) than wild-type mice (Fig. 5B). Ethanol produced anxiolytic effects (displayed increased open-arm activity) in both CREB-haplodeficient and wild-type mice as compared with their respective control groups, but the magnitude of this effect was significantly less in CREB-deficient mice compared with littermate wild-type mice injected with ethanol (Fig. 5B). The general activity of the mice was not altered either by alcohol or normal saline injection or by deletion of the CREB gene as measured by the total number of arm entries in the EPM test (Fig. 5B). We also measured blood ethanol levels $1 \mathrm{hr}$ after ethanol injection. It was found that the mean \pm SEM of blood ethanol levels (milligram percentage) were similar in CREB-haplodeficient and wild-type mice (Fig. 5A). These results indicate that increased ethanol consumption by CREB-haplodeficient mice is not related to differences in ethanol metabolism. The brains from these mice were also analyzed for the measurement of $\mathrm{p}$-CREB and NPY protein levels in the amygdaloid brain structures. It was found that a single alcohol injection after $1 \mathrm{hr}$ significantly increased the p-CREB and NPY protein levels in the central and medial amygdala but not the basolateral amygdala of CREB-haplodeficient and wild-type mice compared with their respective control group; however, the protein levels of p-CREB and NPY were still significantly less in the central and medial amygdala of alcoholinjected CREB-deficient compared with saline-injected wildtype mice (Fig. $5 C$ ). These results suggests that CREB may also play a role in the anxiolytic action of ethanol, and this may be mediated via increased expression of NPY in the central and medial amygdala.

\section{Discussion}

The novel observation of the present study is that CREBhaplodeficient mice have a higher preference for ethanol than their wild-type littermates. The direct relationship between the 


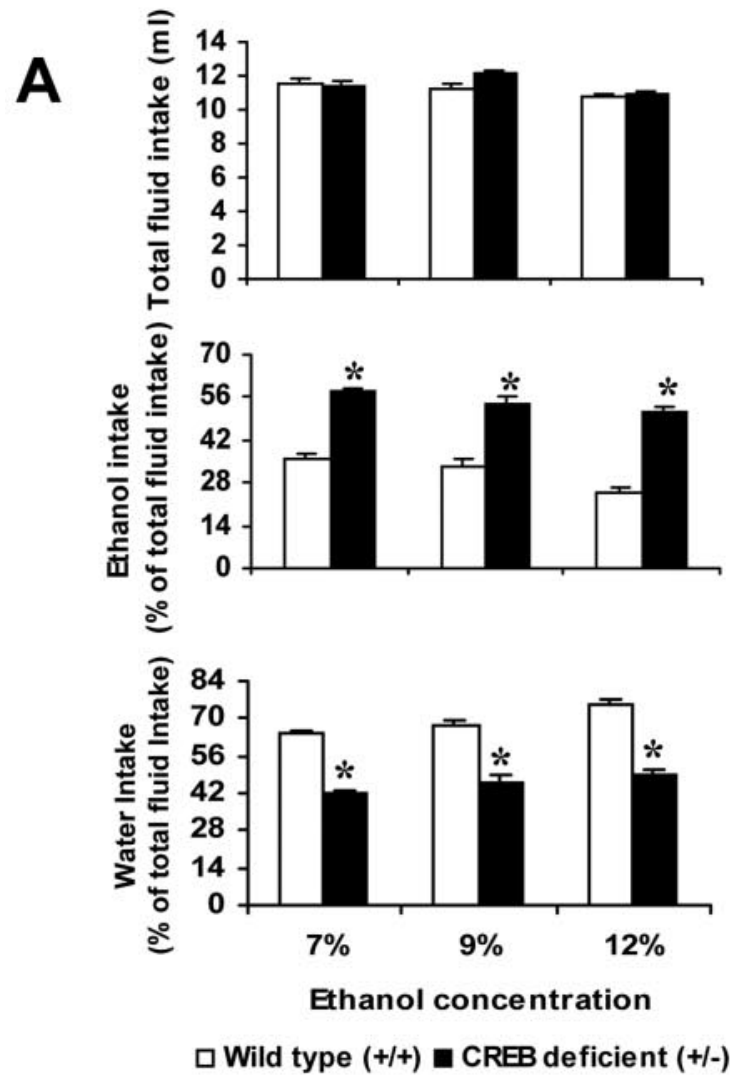

B

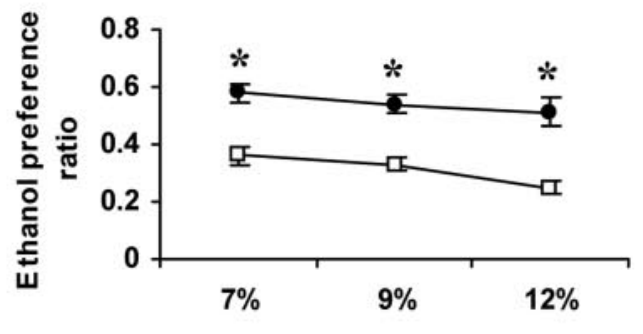

Ethanol concentration
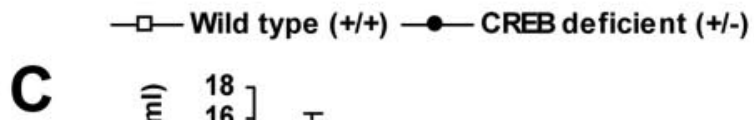

CREB gene deficiency and increased alcohol drinking behaviors is striking. Several previous studies have reported that various components of the cAMP second messenger pathways are important in alcohol dependence and preference (Yang et al., 1998, 2003; Hoffman and Tabakoff, 1990; Thiele et al., 2000; Misra et al., 2001; Yao et al., 2002), but this is the first report that causally implicates the role of the CREB gene in alcohol-drinking behaviors. Another interesting observation of the present study is that CREB-haplodeficient mice displayed more anxiety-like behaviors, and the anxiolytic action of acute ethanol was less in these mice compared with wild-type mice.

There are three isoforms of CREB, namely $\alpha, \Delta$, and $\beta$ (Blendy et al., 1996). The CREB $\alpha$ and $\Delta$ isoforms are the major isoforms in adult brain and play a role in synaptic plasticity (Blendy et al., 1996; Mantamadiotis et al., 2002). The deletion of CREB ( $\alpha$ and $\Delta$ isoforms) in CREB homozygous $(-/-)$ and heterozygous $(+/-)$ knock-out mice leads to a compensatory increase in the levels of the CREB- $\beta$ isoform, a minor isoform (Blendy et al., 1996). The role of the CREB- $\beta$ isoform is not known at the present time because it is less abundant in the adult brain (Blendy et al., 1996). This isoform plays a crucial role during development because if mice lack all three isoforms, they cannot live (Rudolph et al., 1998). CREB ( $\alpha$ and $\Delta$ ) homozygous and heterozygous mice are viable and grow normally without abnormalities in brain histology (Hummler et al., 1994; Blendy et al., 1996). The levels of some isoforms of the cAMP responsive element modulator and the activation transcription factor-1 protein are also increased in CREB $\alpha / \Delta$ homozygous ( $/-)$ mice (Hummler et al., 1994). Despite this upregulation, it has been shown that CREB-DNA binding activity, CREB, and p-CREB levels are reduced ( $~ 90 \%)$ in the brain of CREB $\alpha / \Delta$ homozygous $(-/-)$ knock-out mice (Pandey et al., 2000; Walters and Blendy, 2001; Walters et al., 2003). We extended these studies in CREB heterozygous $(+/-)$ mice and examined the status of total and p-CREB in brain structures of CREB-haplodeficient $(+/-)$ mice. Our data indicate that CREB heterozygous $(+/-)$ mice have $\sim 40 \%$ less total CREB and p-CREB (serine-133) protein levels in the various brain structures that we studied (cortical, hippocampal, amygdaloid, nucleus accumbal, and hypothalamic structures) compared with wild-type mice. These results suggest that p-CREB levels are lower because of decreased levels of total CREB in the brain of CREB-haplodeficient mice. We also found that haplodeletion of CREB $\alpha$ and $\Delta$ genes is associated with the decreased expression of CREB target genes such as NPY and BDNF in the brain structures of CREB-deficient mice compared with wild-type mice. These results clearly suggest that although the CREB- $\beta$ isoform is slightly upregulated in the brain of CREB $\alpha$ - and $\Delta$-haplodeficient mice (Blendy et al., 1996), the protein levels of total CREB and p-CREB and expressions of CREB-related genes such as NPY and BDNF are lower in the brain structures of these mice compared with wild-type mice. Furthermore, reductions in protein levels of CREB, p-CREB, NPY, and BDNF are not caused

\footnotetext{
Figure 4. $A, B$, Ethanol preference $(7,9$, and $12 \%$ ethanol in water solution) measured by the two-bottle free-choice paradigm in CREB-haplodeficient $(+/-)$ and littermate wild-type mice. Values represent the percentage intake of alcohol and water of total daily fluid intake $(A)$ and ethanol consumption $(B)$ relative to total fluid intake (ethanol-preference ratio). Values are the mean \pm SEM of $9-10$ mice in each group. * Significantly different from wild-type mice $(p<0.001)$. C, Sucrose preference (of 2 and $4 \%$ sucrose in water) measured by the two-bottle free-choice paradigm in CREB-haplodeficient $(+/-)$ and littermate wild-type mice. Values represent the percentage intake of sucrose solution of total daily fluid intake. Values are the mean \pm SEM of eight mice in each group.
} 
A
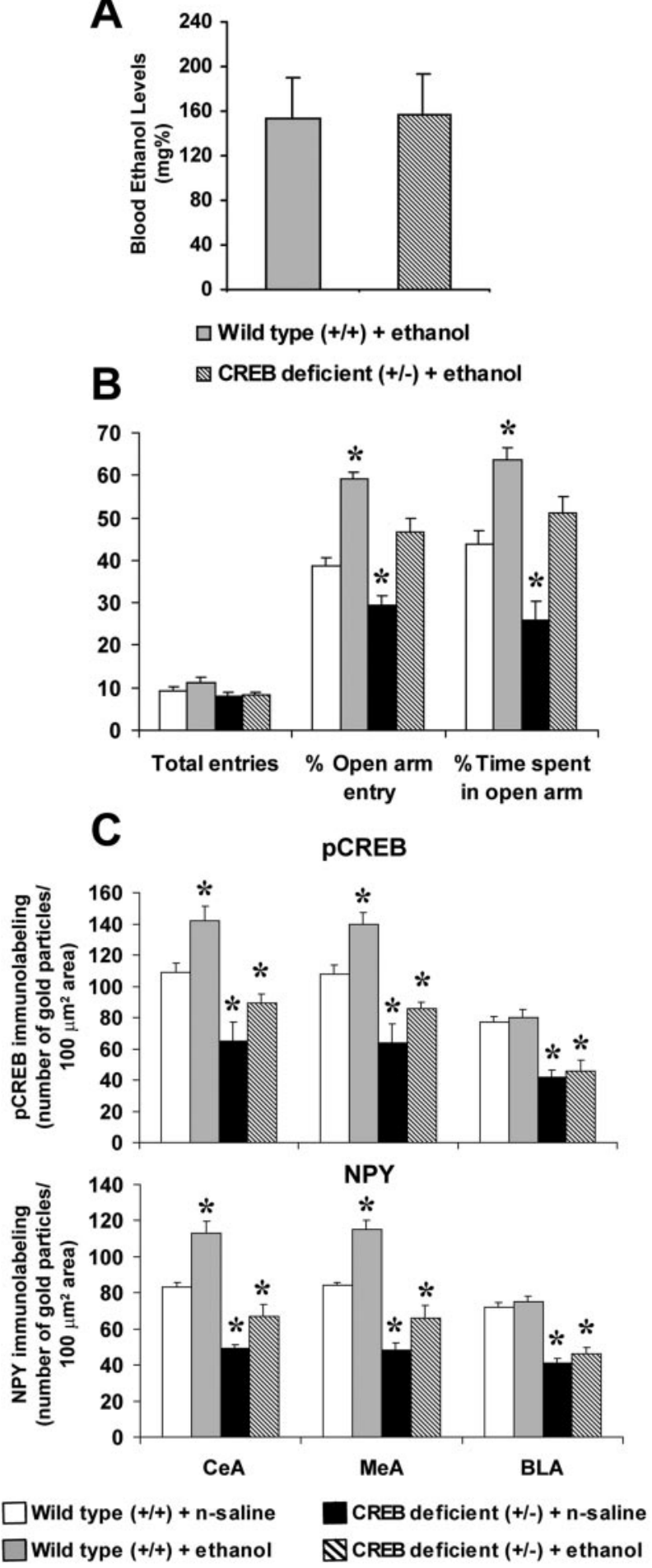

Figure 5. $A$, The blood ethanol levels in CREB-haplodeficient $(+/-)$ and littermate wild-type mice. These mice were injected with ethanol ( $2 \mathrm{gm} / \mathrm{kg}$, i.p.), and $1 \mathrm{hr}$ after the ethanol injection blood ethanol levels (milligram percentage) were measured. Values are the mean \pm SEM of seven mice in each group. $B$, The open- and closed-arm activities of the EPM by CREBhaplodeficient $(+/-)$ mice and littermate wild-type mice injected with ethanol $(2 \mathrm{gm} / \mathrm{kg}$, i.p.) or normal saline. Anxiety-like behaviors were measured $1 \mathrm{hr}$ after the ethanol injection. Values are the mean \pm SEM of seven mice in each group. * Significantly different from wild-type mice $(p<0.05-0.01)$. C, Effects of acute ethanol (1 hr after intraperitoneal injection of $2 \mathrm{gm} / \mathrm{kg}$ ethanol) on $p$-CREB and NPY gold immunolabeling (number of immunogold particles per 100 $\mu \mathrm{m}^{2}$ area) in the amygdaloid brain structures (CeA, MeA, and BLA) of CREB-haplodeficient $(+/-)$ mice and littermate wild-type $(+/+)$ mice. Values are the mean \pm SEM of five mice in each group. *Significantly different from wild-type mice $(p<0.05-0.01)$ by neuronal loss because CREB-haplodeficient mice have numbers of neurons similar to those of wild-type mice.

The nucleus accumbens (NAc) and amygdaloid structures are part of the extended amygdala circuitry and have been associated with rewarding, reinforcing, and motivational aspects of drugs of abuse including ethanol (Koob et al., 1998; Koob, 2000, 2003; McBride, 2002). Because the CREB gene is deleted globally in CREB-haplodeficient mice, it is difficult to pinpoint which neurocircuitry is involved in the actions of CREB on anxiety and alcohol-drinking behaviors of these mice. NAc CREB has been implicated in the preference for morphine and cocaine (Carlezon et al., 1998; Nestler, 2001; Walters and Blendy, 2001; McClung and Nestler, 2003). For example, CREB overexpression in the NAc reduced the rewarding properties of cocaine and morphine (Carlezon et al., 1998; Nestler, 2001). Also, CREB $\alpha / \Delta$ homozygous $(-/-)$ mice show an increased preference for cocaine (Walters and Blendy, 2001). It has been shown that elevating cAMP levels by the infusion of the phosphodiesterase inhibitor (rolipram) into the NAc or intraperitoneal injection of rolipram can block the initiation of cocaine self-administration and alter the brain stimulation reward for cocaine (Knapp et al., 1999, 2001). Chronic voluntary ethanol exposure significantly decreases CREB phosphorylation in the NAc of rats (Misra et al., 2001; Li et al., 2003), and CREB expression and phosphorylation are lower in the shell structures of the NAc but not in other brain structures of $\mathrm{C} 57 \mathrm{BL} / 6$ as compared with DBA/2 mice (Misra and Pandey, 2003). On the other hand, C57BL/6 mice do not display higher anxiety-like behaviors but consume higher amounts of alcohol compared with DBA/2 mice (Misra and Pandey, 2003). Interestingly, overexpression, but not the decreased expression, of CREB in the NAc (shell structures) increases anxiety-like behaviors in rats (Barrot et al., 2002). Taken together, these results suggest that decreased CREB function in the NAc may be involved in increased preference for morphine, cocaine, or ethanol but not in anxiety-like behaviors. In light of these data, it can be suggested that decreased CREB in the NAc of CREBhaplodeficient mice may be involved in the reward mechanisms of alcohol-drinking behaviors but not in anxiety-like behaviors.

Both clinical and epidemiological studies have shown that individuals who are anxious show a greater vulnerability to alcohol abuse (Bibb and Chambless, 1986; Wilson, 1988; Koob, 2003). Amygdaloid brain structures, particularly the CeA, play a crucial role in anxiety and motivational aspects of alcoholdrinking behaviors (Davis, 1997; Koob, 2003). We tested the possibility that CREB-haplodeficient mice may have higher anxiety levels because of lower CREB levels in the amygdala and that they drink more ethanol to self-medicate their higher level of anxiety behaviors. It was found that CREB-haplodeficient $(+/-)$ mice have higher baseline anxiety-like behaviors than their wild-type littermates. Other investigators have also found that CREBhomozygous $(-/-)$ mice displayed more anxiety-like behaviors (Graves et al., 2002). Interestingly, acute ethanol exposure produces anxiolytic effects in wild-type mice, and this effect is attenuated in CREB-haplodeficient mice. We also measured the p-CREB and NPY protein levels in amygdaloid structures and found that acute ethanol exposure significantly increased p-CREB and NPY protein levels in the central and medial but not the basolateral amygdala of wild-type mice. The ethanol exposure tended to increase but not completely normalize the p-CREB and NPY protein levels in the central and medial amygdala of CREBdeficient mice. These results suggest that CREB is crucial in the anxiolytic action of ethanol. Several studies support the possibility that CREB-haplodeficient mice display anxiety and alcohol- 
drinking behaviors because of the decreased expression of NPY in their amygdaloid brain structures. For example, NPY infusion into the CeA produces anxiolytic effects in rats (Heilig et al., 1993), and NPY null (-/-) mutant mice display more anxietylike behaviors (Palmiter et al., 1998) and consume larger amounts of ethanol than wild-type mice (Thiele et al., 1998). More recently, we observed that inhibition of CREB phosphorylation in the CeA via a PKA inhibitor causes a reduction in the expression of NPY. Behaviorally, these rats display more anxietylike behaviors and have a higher preference for ethanol. On the other hand, infusions of exogenous NPY into the CeA prevent PKA inhibitor-induced increased ethanol preference in rats (Pandey et al., 2003a,b). It has been shown that CREB phosphorylation and NPY expression are lower in rat amygdaloid and cortical structures during withdrawal after chronic ethanol exposure (Pandey et al., 2001, 2003b; Zhang and Pandey, 2003). Infusions of PKA activator into the CeA during ethanol withdrawal significantly normalized the reduction in CREB phosphorylation and NPY expression and also prevented the development of anxiety-like behaviors in rats (Pandey et al., 2003b; Zhang and Pandey, 2003). Furthermore, CREB expression and phosphorylation and NPY expression are lower in the central and medial amygdala of P compared with NP rats, and voluntary ethanol intake significantly increased CREB phosphorylation and NPY expression in the central and medial amygdala and also decreased the anxiety-like behaviors of P rats (Pandey et al., 2003a; our unpublished observations). These results suggest clearly that decreased CREB phosphorylation in the central and medial amygdala may be involved in anxiety-like behaviors and that ethanolwithdrawn rats or P rats or CREB-haplodeficient mice consume more ethanol to maintain normal CREB function, thereby decreasing anxiety-like behaviors.

BDNF, another CREB target gene, plays an important role in synaptic plasticity (Shieh et al., 1998; Schinder and Poo, 2000). It has been shown recently that the BDNF gene is involved in alcohol abuse (Uhl et al., 2001), and BDNF-haplodeficient mice also have a higher preference for ethanol (Hensler et al., 2003). Furthermore, BDNF conditional knock-out mice are more prone to anxiety-like behaviors (Rios et al., 2001). Thus it is also possible that higher ethanol preference or anxiety-like behaviors in CREB-haplodeficient mice may be related to the decreased expression of BDNF in the various brain structures of these mice.

\section{Conclusions}

The data collected here provide direct evidence to suggest that deletion (one allele) of CREB $\alpha$ and $\Delta$ genes promotes alcoholdrinking and anxiety-like behaviors. This deletion is also associated with decreased expression of two prominent CREB-related genes; i.e., NPY and BDNF. These results indicate that CREBhaplodeficient $(+/-)$ mice may be an important molecular model for understanding the landscape of potential CREB target genes and their concomitant role in anxiety and alcohol-drinking behaviors. Future studies will be directed at investigating the role of the NPY and BDNF genes and several other CREB-related genes (Lonze and Ginty, 2002; McClung and Nestler, 2003) in the anxiety and alcohol-drinking behaviors of CREBhaplodeficient mice.

\section{References}

Barrot M, Olivier JD, Perrotti LI, DiLeone RJ, Berton O, Eisch AJ, Impey S, Storm DR, Neve RL, Yin JC, Zachariou V, Nestler EJ (2002) CREB activity in the nucleus accumbens shell controls gating of behavioral responses to emotional stimuli. Proc Natl Acad Sci USA 99:11435-11440.
Bibb J, Chambless DL (1986) Alcohol use and abuse among diagnosed agoraphobics. Behav Res Ther 24:49-58.

Bison S, Crews F (2003) Alcohol withdrawal increases neuropeptide Y immunoreactivity in rat brain. Alcohol Clin Exp Res 27:1173-1183.

Blendy JA, Kaestner KH, Schmid W, Gass P, Schutz G (1996) Targeting of the CREB gene leads to up-regulation of a novel CREB mRNA isoform. EMBO J 15:1098-1106.

Bourtchuladze R, Frenguelli B, Blendy J, Cioffi D, Schutz G, Silva AJ (1994) Deficient long-term memory in mice with a targeted mutation of the cAMP-responsive element-binding protein. Cell 79:59-68.

Carlezon WA, Thome J, Olson VG, Lane-Ladd SB, Brodkin ES, Hiroi N, Duman RS, Neve RL, Nestler EJ (1998) Regulation of cocaine reward by CREB. Science 282:2272-2275.

Cloninger CR (1987) Neurogenetic adaptive mechanisms in alcoholism. Science 236:410-416.

Davis M (1997) Neurobiology of fear responses: the role of the amygdala. J Neuropsychiatry Clin Neurosci 9:382-402.

Graves L, Dalvi A, Lucki I, Blendy JA, Abel T (2002) Behavioral analysis of CREB $\alpha \Delta$ mutation on B6/129 F1 hybrid background. Hippocampus 12:18-26.

Heilig M, McLeod S, Brot M, Heinrichs SC, Menzaghi F, Koob GF, Britton KT (1993) Anxiolytic-like action of neuropeptide Y: mediation by Y1 receptor in amygdala and dissociation from food intake effects. Neuropsychopharmacology 8:357-363.

Hensler JG, Ladenheim E, Lyons WE (2003) Ethanol consumption and serotonin-1A (5-HT1A) receptor function in heterozygous BDNF $(+/-)$ mice. J Neurochem 85:1139-1147.

Hoffman PL, Tabakoff B (1990) Ethanol and guanine nucleotide binding proteins: a selective interaction. Fed Am Soc Exp Biol J 4:2612-2622.

Hummler E, Cole TJ, Blendy JA, Ganss R, Aguzzi A, Schmid W, Beermann F, Schutz G (1994) Targeted mutation of the CREB gene: compensation within the CREB/ATF family of transcription factors. Proc Natl Acad Sci USA 91:5647-5651.

Hwang BH, Zhang J-K, Ehlers CL, Lumeng L, Li T-K (1999) Innate differences of neuropeptide Y (NPY) in hypothalamic nuclei and central nucleus of the amygdala between selectively bred rats with high and low alcohol preference. Alcohol Clin Exp Res 23:1023-1030.

Impey S, Obrietan K, Storm DR (1999) Making new connections: role of ERK/MAP kinase signaling in neuronal plasticity. Neuron 23:11-14.

Li J, Li Y-H, Yuan X-R (2003) Changes of phosphorylation of cAMP response element binding protein in rat nucleus accumbens after chronic ethanol intake: naloxone reversal. Acta Pharmacol Sin 24:930-936.

Knapp CM, Foye MM, Ciraulo DA, Kornetsky C (1999) The type IV phosphodiesterase inhibitors, Ro20-1724 and rolipram, block the initiation of cocaine self-administration. Pharmacol Biochem Behav 62:151-158.

Knapp CM, Lee K, Foye M, Ciraulo DA, Kornetsky C (2001) Additive effects of intra-accumbens infusion of the cAMP specific phosphodiesterase inhibitor, rolipram and cocaine on brain stimulation reward. Life Sci 69:1673-1682.

Koob GF (2000) Neurobiology of addiction. Toward the development of new therapies. Ann NY Acad Sci 909:170-185.

Koob GF (2003) Alcoholism: allostasis and beyond. Alcohol Clin Exp Res 27:232-243.

Koob GF, Sanna PP, Bloom FE (1998) Neuroscience of addiction. Neuron 21:467-476.

Li T-K, Lumeng L, Doolittle DP (1993) Selective breeding for alcohol preference and associated responses. Behav Genet 23:163-170.

Lonze BE, Ginty DD (2002) Function and regulation of CREB family transcription factors in the nervous system. Neuron 35:605-623.

MacLennan AJ, Lee N, Walker DW (1995) Chronic ethanol administration decreases brain-derived neurotrophic factor gene expression in the rat hippocampus. Neurosci Lett 197:105-108.

Maldonado R, Blendy JA, Tzavara E, Gass P, Roques BP, Hanoune J, Schutz G (1996) Reduction of morphine abstinence in mice with a mutation in the gene encoding CREB. Science 273:657-659.

Mantamadiotis T, Lemberger T, Bleckmann SC, Kern H, Kretz O, Martin Villalba A, Tronche F, Kellendonk C, Gau D, Kapfhammer J, Otto C, Schmid W, Schutz G (2002) Disruption of CREB function in brain leads to neurodegeneration. Nat Genet 31:47-54.

McBride WJ (2002) Central nucleus of the amygdala and the effects of alcohol and alcohol-drinking behavior in rodents. Pharmacol Biochem Behav 71:509-515. 
McClung CA, Nestler EJ (2003) Regulation of gene expression and cocaine reward by CREB and delta FosB. Nat Neurosci 6:1208-1215.

Misra K, Pandey SC (2003) Differences in basal levels of CREB and NPY in nucleus accumbens regions between C57BL/ 6 and DBA/2 mice differing in inborn alcohol drinking behavior. J Neurosci Res 74:967-975.

Misra K, Roy A, Pandey SC (2001) Effects of voluntary ethanol intake on the expression of $\mathrm{Ca}^{2+} /$ calmodulin-dependent protein kinase IV and on CREB expression and phosphorylation in the rat nucleus accumbens. NeuroReport 12:4133-4137.

National Institute on Alcohol Abuse and Alcoholism (1993) Eighth Special Report to the Congress on Alcohol and Health, DHHS publication No. ADM 281-91-003, Bethesda, MD.

Nestler EJ (2001) Molecular basis of long-term plasticity underlying addiction. Nat Rev Neurosci 2:119-128.

Palmiter RD, Erickson JC, Hollopeter G, Baraban SC, Schwartz MW (1998) Life without neuropeptide Y. Recent Prog Horm Res 53:163-199.

Pandey SC (2003) Anxiety and alcohol abuse disorders: a common role for CREB and its target, the neuropeptide Y gene. Trends Pharmacol 24:456-460.

Pandey SC, Mittal N, Lumeng L, Li T-K (1999) Involvement of the cyclic AMP-responsive element binding protein gene transcription factor in genetic preference for alcohol drinking behavior. Alcohol Clin Exp Res 23:1425-1434.

Pandey SC, Mittal N, Silva AJ (2000) Blockade of cyclic AMP-responsive element DNA binding in the brain of CREB $\Delta / \alpha$ mutant mice. NeuroReport 11:2577-2580.

Pandey SC, Roy A, Mittal N (2001) Effects of chronic ethanol intake and its withdrawal on the expression and phosphorylation of the CREB gene transcription factor in rat cortex. J Pharmacol Exp Ther 296:857-868.

Pandey SC, Carr CG, Heilig M, Ilveskoski E, Thiele TE (2003a) Neuropeptide $\mathrm{Y}$ and alcoholism: genetic, molecular, and pharmacological evidence. Alcohol Clin Exp Res 27:149-154.

Pandey SC, Roy A, Zhang H (2003b) The decreased phosphorylation of cyclic adenosine monophosphate (cAMP) response element binding (CREB) protein in the central amygdala acts as a molecular substrate for anxiety related to ethanol withdrawal in rats. Alcohol Clin Exp Res 27:396-409.

Radel M, Goldman D (2001) Pharmacogenetics of alcohol response and alcoholism: the interplay of genes and environmental factors in thresholds for alcoholism. Drug Metab Dispos 29:489-494.

Rios M, Fan G, Fekete C, Kelly J, Bates B, Kuehn R, Lechan RM, Jaenisch R (2001) Conditional deletion of brain derived neurotrophic factor in the postnatal brain leads to obesity and hyperactivity. Mol Endocrinol 15:1748-1757.

Roy A, Pandey SC (2002) The decreased cellular expression of neuropeptide $Y$ protein in rat brain structures during ethanol withdrawal after chronic ethanol exposure. Alcohol Clin Exp Res 26:796-803.
Rudolph D, Tafuri A, Gass P, Hammerling GJ, Arnold B, Schutz G (1998) Impaired fetal $\mathrm{T}$ cell development and perinatal lethality in mice lacking the cAMP response element binding protein. Proc Natl Acad Sci USA 95:4481-4486.

Schinder AF, Poo MM (2000) The neurotrophin hypothesis for synaptic plasticity. Trends Neurosci 23:639-645.

Shieh PB, Hu S-C, Bobb K, Timmusk T, Ghosh A (1998) Identification of a signaling pathway involved in calcium regulation of BDNF expression. Neuron 20:727-740.

Silva AJ, Kogan JH, Frankland PW, Kida S (1998) CREB and memory. Annu Rev Neurosci 21:127-148.

Soderling TR (1999) The $\mathrm{Ca}^{2+}$-calmodulin-dependent protein kinase cascade. Trends Biochem Sci 24:232-236.

Stewart RB, Gatto GJ, Lumeng L, Li T-K, Murphy JM (1993) Comparison of alcohol preferring $(\mathrm{P})$ and nonpreferring $(\mathrm{NP})$ rats on tests of anxiety and for anxiolytic effects of ethanol. Alcohol 10:1-10.

Thiele TE, Marsh DJ, Ste Marie L, Berstein IL, Palmiter RD (1998) Ethanol consumption and resistance are inversely related to neuropeptide $\mathrm{Y}$ levels. Nature 396:366-369.

Thiele TE, Willis B, Stadler J, Reynolds JG, Bernstein IL, McKnight GS (2000) High ethanol consumption and low sensitivity to ethanol-induced sedation in protein kinase A-mutant mice. J Neurosci 20:RC75(1-6).

Thome J, Gewirtz JC, Weijers HG, Weisbeck GA, Henn FA (2000) Genome polymorphism and alcoholism. Pharmacogenomics 1:63-71.

Uhl GR, Liu QR, Walther D, Hess J, Naiman D (2001) Polysubstance abusevulnerability genes: genome scans for association, using 1,004 subjects and 1,494 single-nucleotide polymorphisms. Am J Hum Genet 69:1290-1300.

Walters CL, Blendy JA (2001) Different requirements for cAMP response element-binding protein in positive and negative reinforcing properties of drugs of abuse. J Neurosci 21:9438-9444.

Walters CL, Kuo Y-C, Blendy JA (2003) Differential distribution of CREB in the mesolimbic dopamine reward pathway. J Neurochem 87:1237-1244.

Wilson GT (1988) Alcohol and anxiety. Behav Res Ther 26:369-381.

Yang X, Horn K, Baraban JM, Wand GS (1998) Chronic ethanol administration decreases phosphorylation of cyclic AMP-response element binding protein in granule cells of rat cerebellum. J Neurochem 70:224-232.

Yang X, Oswald L, Wand G (2003) The cyclic AMP/protein kinase A signal transduction pathway modulates tolerance to sedative and hypothermic effects of ethanol. Alcohol Clin Exp Res 27:1220-1225.

Yao L, Arolfo MP, Dohrman DP, Jiang Z, Fan P, Fuchs S, Janak PH, Gordon AS, Diamond I (2002) Beta gamma dimers mediate synergy of dopamine D2 and adenosine A2 receptor-stimulated PKA signaling and regulate ethanol consumption. Cell 109:733-743.

Zhang H, Pandey SC (2003) Effects of PKA modulation on the expression of neuropeptide $\mathrm{Y}$ in rat amygdaloid structures during ethanol withdrawal. Peptides 24:1397-1402. 